\title{
ROSARIO ARDE. FAMILIARES DE VÍCTIMAS Y SU RELACIÓN CON EL ESTADO EN EL MARCO DE UNA CATÁSTROFE
}

\section{Rosario arde. Families of victims and their relationship with the State around a catastrophe}

\author{
Carolina Schillagi* \\ * Universidad Nacional de General Sarmiento (Argentina) \\ cschillagi@gmail.com
}

\section{Palabras clave}

Movimientos de víctimas Catástrofes Reclamos

\section{Keywords}

Victims movements Catastrophes Claims

\begin{abstract}
Resumen
El artículo analiza el proceso de movilización de familiares de víctimas en torno a una catástrofe ocurrida en Rosario, Argentina, en 2013. Las maniobras para la reparación de una fuga de gas en un edificio céntrico de la ciudad causaron la explosión de una torre de edificios dejando un saldo de 22 personas muertas y numerosos heridos. Partiendo de la exploración de los grupos que se conformaron luego del hecho para reclamar justicia y señalar las responsabilidades frente a lo ocurrido, tengo como objetivo evidenciar el proceso de producción social de las víctimas. Para ello busco dar respuesta a los siguientes interrogantes: ¿De qué manera un grupo de personas se considera a sí mismo y es considerado por otros como víctimas de un daño evitable? ¿Cuál es el papel del Estado en dicho proceso y qué posiciones adoptan los familiares frente a los diferentes dispositivos estatales que se ponen en marcha en el marco de determinados eventos catastróficos? La perspectiva utilizada se apoya en los estudios de movilizaciones de víctimas, haciendo especial hincapié en la noción de dispositivo, así como en aportes que reflexionan sobre las catástrofes y las víctimas de desastres. Para lograr los objetivos se ha realizado un trabajo de corte cualitativo, basado en entrevistas en profundidad a actores claves, observación de reuniones y análisis de fuentes periodísticas y documentos oficiales.
\end{abstract}

\section{Abstract}

The article analyzes the process of mobilization by family members of victims of a catastrophe that happened in Rosario, Argentina, in 2013. The repairing of a gas leak in a building in the center of the city caused an explosion in an apartment tower killing 22 people and leaving a great number of injured people. Through an exploration of the groups created after the explosion to claim justice and to adjudicate responsibilities for what happened, my aim is to show the process of social production of the victims as such. Accordingly, I want to answer the following questions: In what way does a group of people consider themselves and are considered by others as victims of a preventable damage? What is the role of the State in such process? What positions do family members take when they have to confront different state mechanisms implemented in the context of some specific catastrophes? Our point of view stands on studies about victim actions, primarily highlighting the idea of mechanism as well as the contributions reflecting on catastrophes and victims of disaster. In order to achieve these goals, we have performed a qualitative work, based on deep interviews with key informants, observation at meetings, and analysis of press sources and official documents.

Schillagi, C. (2017). Rosario arde. Familiares de víctimas y su relación con el Estado en el marco de una catástrofe. Papeles del CEIC, vol. 2017/1, papel 165, CEIC (Centro de Estudios sobre la Identidad Colectiva), UPV/EHU Press, http://dx.doi.org/10.1387/pceic.16937 


\section{INTRODUCCIÓN}

Como parte de una política de privatización de los principales servicios públicos que tuvo lugar durante la década del noventa del siglo $X X$ en la Argentina, el suministro del servicio de gas pertenece en la provincia de Santa Fe a la empresa Litoral Gas ${ }^{1}$. En el año 2013, las maniobras de reparación de una válvula que realizaban gasistas matriculados en un edificio de la ciudad de Rosario, ocasionaron una fuga desatando una explosión que resultó en el fallecimiento de 22 personas, más de 60 heridos y 238 casas o departamentos afectados. Los días previos y el mismo día de la explosión, vecinos del edificio realizaron llamados a la empresa para notificar la fuga y solicitar el corte del servicio pero no fueron atendidos. Lo sucedido colocó en el centro del debate público el papel de la empresa privada y la responsabilidad política del Estado y de sus distintos niveles de gobierno en el control y regulación del funcionamiento de empresas que proveen de servicios públicos ${ }^{2}$. El debate tuvo lugar tras la relación de hechos catastróficos ocurridos en Argentina por negligencia, falta de inversión o fallas en la seguridad de los servicios mencionados anteriormente ${ }^{3}$.

A las 9:38 de la mañana del 6 de agosto de 2013, un gasista y su ayudante estaban cambiando el regulador de gas cuando se produjo un escape del fluido causando la explosión que en pocos minutos arrasó con una de las tres torres de un complejo de edificios ubicados en pleno centro de Rosario, la tercera ciudad más grande de la Argentina con un millón de habitantes. El efecto fue tal, que la onda expansiva se diseminó por varias cuadras a la redonda y la explosión se escuchó casi a 50 cuadras del epicentro.

\footnotetext{
${ }^{1}$ Es importante tener en cuenta que en la Argentina los principales servicios públicos (gas, agua, electricidad, ferrocarriles, telecomunicaciones, entre otros) fueron privatizados durante los años noventa y que algunas de esas empresas continúan siendo propiedad de distintos grupos empresariales. En el caso del gas la empresa mencionada comenzó a operar a principios de los noventa y continúa haciéndolo.

${ }^{2}$ La Argentina tiene tres niveles de gobierno: local o municipal, provincial y nacional. Los estados provinciales conservan su autonomía, a pesar de estar reunidos bajo un gobierno común (gobierno nacional).

${ }^{3}$ El más cercano en el tiempo es el accidente ferroviario que tuvo lugar en la estación de Once de la Capital Federal, en el año 2012. En él fallecieron más de 50 personas y unas 700 resultaron heridas. La empresa Trenes de Buenos Aires (TBA) tenía la concesión para operar el servicio de pasajeros desde el año 1995. Luego del accidente de 2012 se le rescindió el contrato mediante un decreto presidencial.
} 
Fueron pasando las horas y los días y el operativo de rescate permitió conocer el número definitivo de víctimas fatales así como aquellos que resultaron seriamente damnificados por la explosión, ya fueran residentes del edificio que no se encontraban allí en el momento del siniestro o personas que vivían y/o trabajaban en locales comerciales linderos o cercanos.

Luego de conocerse el número definitivo de fallecidos, se fue conformando un grupo de familiares que comenzó a reclamar la dilucidación de lo sucedido y a señalar las responsabilidades que consideraban pertinentes. Un conjunto de actores y de entidades de diversa índole entraron en contacto: los propios familiares, los damnificados, vecinos de la zona, militantes de agrupaciones gremiales y estudiantiles, medios de comunicación, bomberos y rescatistas, especialistas en catástrofes, autoridades políticas, equipos de salud mental, instituciones y organizaciones sociales representativas de distintos sectores de la ciudad, médicos, abogados, ingenieros, funcionarios judiciales.

El análisis de este hecho tiene un doble objetivo. Por una parte, explorar el proceso de producción social de las víctimas, es decir, los distintos modos en que un grupo de personas, en este caso familiares directos, se considera a sí mismo y es considerado por otros actores sociales, explícita e implícitamente, como víctimas de un daño evitable. Por otro lado, analizar el tipo de vinculaciones que fueron estableciendo los familiares con las autoridades políticas a través de diferentes dispositivos y acciones públicas.

Para alcanzar ambos objetivos, se reconstruyó el proceso de conformación del grupo de familiares de víctimas fatales de la explosión, realizando entrevistas en profundidad a actores claves, observación de encuentros y reuniones en sede judicial, intervenciones de actores en jornadas académicas, material de prensa e informes de legisladores ${ }^{4}$.

En una primera parte se exponen muy brevemente algunas de las perspectivas teóricas más significativas para comprender los procesos aquí presentados, tanto con relación a la movilización de familiares de

\footnotetext{
${ }^{4}$ El artículo retoma algunos aspectos de una investigación más amplia, llevada adelante en el marco de un proyecto financiado por la Agencia Nacional de Promoción Científica y Tecnológica (ANPCyT) de la Argentina.
} 
víctimas como a las catástrofes como objetos de estudio. En una segunda parte, se reconstruyen y describen las principales controversias entre los grupos de familiares de fallecidos y de damnificados por la explosión y los modos en que se fueron diferenciando. En una tercera, se describen y analizan los modos de relación entre familiares y Estado, a través de las posturas y evaluaciones que los primeros realizaron frente a distintos dispositivos. Finalmente, se ofrecen algunas reflexiones de carácter general sobre el proceso de producción social de las víctimas y de las formas en que interactúan familiares y dispositivos estatales.

\section{PeRspectivas teóricas SOBRe MOVILIZACIONES DE VÍctimas y ESTUDIOS SOBRE DESASTRES O CATÁSTROFES}

Los estudios sobre movilizaciones de víctimas se caracterizan por cruzar varios campos disciplinarios como la antropología, la sociología, la psiquiatría, los estudios culturales, entre otros. Los enfoques dentro de cada campo son diversos, algunos más orientados por las teorías de la acción colectiva, otros por enfoques que hacen centro en los dispositivos, en la constitución de problemas públicos, en el papel de los científicos o expertos. Dadas las características del caso que abordo aquí, los trabajos que tienen como objeto de estudio a las catástrofes también constituyen una herramienta de apoyo para pensar esos fenómenos de movilización de víctimas.

Los estudios sobre catástrofes y desastres pueden colaborar en establecer un diálogo o acercar pistas para la construcción del objeto de estudio, es decir, la producción social de la figura de las víctimas. En trabajos recientes, se pone de relieve la necesidad de un análisis de las causas profundas de persistencia de los desastres (Oliver-Smith et al., 2016). En tal sentido, se destacan los factores que pesan tanto a nivel político o gubernamental (el manejo de la emergencia o la atención post-catástrofe) como a nivel privado (los beneficios económicos en detrimento de la inversión en seguridad y regulación de determinados servicios, por ejemplo).

Por otra parte, una socioantropología de las catástrofes se propone estudiarlas no como fenómenos secundarios sino como objetos de estudio plenos o principales. Es decir, como grillas de lectura del mundo no sólo centradas en las cuestiones de la vulnerabilidad o la exigencia de respuesta, sino como fenómenos que integran la cultura (Clavandier, 
2010). En tal sentido, la catástrofe posee un alcance heurístico que va más allá de su carácter de puro evento disruptivo. Las nociones en torno a las cuales se articula el campo de los estudios sobre catástrofes o desastres son múltiples: vulnerabilidad, riesgo, "evento crítico", sufrimiento social.

En este texto tomaré en cuenta especialmente las perspectivas que desarrollan la noción de dispositivo y dentro de ellas, las que prestan especial atención a las distintas formas en que los individuos y los grupos se posicionan frente a dispositivos ${ }^{5}$ de diversa índole realizando evaluaciones, encontrando límites o apoyándose en éstos para llevar adelante sus reclamos (Barbot y Dodier, 2016). Asimismo, tendré en cuenta algunos aportes de trabajos que reflexionan sobre las catástrofes y las víctimas a fin de comprender y situar la especificidad del caso que presento.

\section{CONTROVERSIAS Y CONFORMACIÓN DE GRUPOS DE VÍCTIMAS}

\subsection{Ejes de diferenciación: familia, emociones, objetos y autenticidad}

Luego de hallar sin vida a las últimas tres personas que estaban siendo buscadas, el día 13 de agosto finalizó el operativo de rescate desplegado en el lugar. De allí en adelante, comenzaron una serie de acciones públicas de los familiares en diversos ámbitos (político, judicial, mediático, académico, etc.) y que adquirieron formatos diferentes a lo largo del tiempo.

La trama de actores que tomaron parte en la configuración del caso es compleja, lo cual hace necesario trazar una suerte de esquema para poder facilitar la lectura y comprensión de sus vinculaciones. En un

\footnotetext{
${ }^{5}$ Un dispositivo será considerado aquí en los términos en que proponen Barbot y Dodier (2016), es decir, como un encadenamiento ya preparado de secuencias, destinado a calificar o transformar un estado de cosas por intermedio de un agenciamiento de elementos tanto materiales como lingüísticos (2016: 431). Para el estudio de los dispositivos sugieren adoptar un enfoque procesual y orientado a la atribución de finalidades realizada por todo tipo de actores que entran en contacto con éstos, pero sin prejuzgar finalidades esenciales de los mismos. Un dispositivo puede ponerse en marcha a lo largo de una extensión temporal variable e involucrar a los que cumplen distintos roles con relación a él: los que lo conciben, los que lo ponen en funcionamiento y los que son objeto del mismo.
} 
tramo inicial (durante el primer mes luego de la explosión) se conformaron dos grupos: la "Asociación Salta 2141 Familiares de Víctimas", que concentraba a los familiares de fallecidos en la explosión y la "Asociación 6 de Agosto" integrada por sobrevivientes, damnificados, afectados y familiares de personas fallecidas. De estas asociaciones, como se verá, sólo la primera tuvo continuidad en el tiempo.

Para poder centrarme en la relación de los familiares de víctimas con algunas de las instancias estatales, intento sintetizar la vasta gama de interlocutores que estuvieron involucrados. En esa red intervinieron la mencionada empresa Litoral Gas, asociaciones de gasistas matriculados, empresas de seguros, el Ente Nacional Regulador del Gas (ENARGAS), los niveles municipales, provinciales y nacionales de gobierno, instituciones de salud mental públicas y privadas. Los familiares tomaron contacto con otras agrupaciones de víctimas, colectivos militantes y organizaciones sociales. El poder judicial fue otro interlocutor destacado. Además, los familiares se contactaron con la Auditoría General de la Nación (AGN) ${ }^{6}$.

El proceso por el que fueron tomando contacto los familiares de las víctimas fue paulatino. Algunos entrevistados relatan que en las primeras marchas todavía no se conocían y que "en algún momento" se pasaron los teléfonos y se contactaron y convocaron a través de redes sociales. Otros se conocieron en el centro de emergencias médicas donde se había centralizado la información, mientras esperaban saber si sus familiares se hallaban con vida, si estaban internados o si habian fallecido. Otros nunca se conocieron. Como relata Valeria, la madre de un joven fallecido: "Nunca estuvimos los familiares de los 22" (Entrevista de la autora a Mara y Valeria, Rosario, 29/07/15) ${ }^{7}$. En efecto, de las familias de las 22 víctimas fatales, sólo 5 de ellas se constituyeron como querellantes en la justicia. Y a lo largo de los tres años que median hasta el presente, sólo 4 familiares tuvieron un papel público destacado como portavoces del grupo. Es decir que un mismo acontecimiento, catalogado de forma unánime por la opinión pública como la "peor

\footnotetext{
${ }^{6}$ Se trata de un "organismo constitucional con autonomía funcional que asiste técnicamente al Congreso de la Nación en el ejercicio del control externo del Sector Público Nacional mediante la realización de auditorías y estudios especiales". Consultable en: http://www.agn.gov.ar. Última consulta: 22/12/16.

${ }^{7}$ Los nombres de los/las entrevistados/das han sido cambiados para preservar su anonimato.
} 
tragedia de la historia de la ciudad", no generó ninguna reacción común extensiva a todos los familiares de quienes habían perdido la vida a causa de él. Por lo tanto, resulta insuficiente la explicación que atribuye únicamente a la catástrofe la capacidad de constituir el motor de la acción colectiva y sobre todo, de impulsar agrupaciones de víctimas legitimadas por el dolor. Retomaré este punto posteriormente, cuando desarrolle el análisis acerca de las vinculaciones que establecieron los familiares con las instancias políticas.

En los meses siguientes al siniestro, se conformaron las agrupaciones referidas al inicio del apartado. Los contactos entre ambos grupos fueron conflictivos y no prosperaron en una unificación ni en acciones conjuntas. Entre ellas existían diferencias notables.

1) Una primera cuestión de diferenciación era el vínculo familiar con las víctimas. Éste suponía, como se ha visto, una primera distinción entre los que habian perdido familiares directos frente a los que habian sufrido daños materiales o físicos.

La asociación civil "6 de Agosto" se conformó en noviembre de 2013 y sus integrantes se reunían en la Mutual Cristiana, una institución cercana al lugar de la explosión. Las personas que la conformaron se autodenominaban "sobrevivientes, damnificados o afectados". En general, excepto en el caso de la viuda de un fallecido en la explosión, eran aquellos que no se encontraban en el edificio al momento del siniestro pero vivían allí o personas que vivían o trabajaban en lugares linderos o cercanos y habían sufrido daños de diversa índole. Según declaraba el principal vocero y entonces presidente de la asociación, sus objetivos se dirigían sobre todo a paliar las secuelas de la explosión.

Ambas asociaciones protagonizaron controversias en torno a la pertinencia de su liderazgo en acciones públicas conjuntas o con relación a iniciativas de organización interna. Algunas de ellas fueron públicas y otras quedaron en el ámbito de las primeras reuniones, tal como fue referido por varios entrevistados. Los conflictos o disputas por la conducción del grupo, la orientación y/o la índole de los reclamos colaboraron en marcar uno de los ejes centrales de diferenciación e identidad del grupo: el vínculo familiar con los fallecidos otorgó la legitimidad necesaria para erigirse en voces autorizadas frente a las autoridades políticas y obtener el apoyo de la opinión pública. 
2) Un segundo eje de diferenciación estaba vinculado a una doble cuestión: el papel de las emociones en el reclamo público y la relación con los objetos. En ese sentido, el principal referente de la Asociación civil "6 de agosto", Gonzalo Tellería, en una nota periodística, expresaba:

"Todos entendemos lo que significa la pérdida de un familiar directo, pero eso podía llevar a una escalada violenta. En su momento nos reunimos y se lo planteamos (...) pero sentimos que no teníamos derecho a hacer el reclamo juntos porque nos planteaban una escala de dolor en la que una persona fallecida es más importante que nuestro dolor, nos decían que nosotros habíamos perdido un sillón únicamente" ${ }^{8}$.

Al día siguiente de la publicación de las expresiones de Tellería, Mara, viuda de uno de los 22 fallecidos en el incendio, le respondió en el mismo medio de prensa.

"Si somos violentos porque gritamos, puteamos o llevamos un aerosol es porque hace nueve meses que nadie nos da una mano (...) Que nos interpelen por nuestra forma de lucha, cuando ellos no hacen nada, la verdad, es una falta de respeto (...). La gente está sensible por los muertos de calle Salta, no por el que se le rompió el departamento. (...) Si ellos están dolidos, el nuestro es un dolor superior"

Las diferencias con el grupo de sobrevivientes, como ha trabajado Zenobi (2014) con relación al incendio de Cromañón, ofrecen la ocasión de asomarse a las actividades que realizan los actores para legitimar su condición de víctimas. Por un lado, la acreditación del vínculo ante el Estado (partidas de nacimiento, documentos, etc.) es un elemento que ayuda a demostrar una relación previa (ser padres, madres, hermanos, esposas) sólo que naturalizada a lo largo del tiempo. En ese sentido, las acciones de los "sobrevivientes" para que sus situaciones fueran consideradas públicamente como dolorosas ( $y$ por ende legítimas) conllevaba un esfuerzo adicional: el de tener que demostrar o probar que las pérdidas o daños sufridos se correspondian con el siniestro (por ejemplo, que los registros catastrales atestiguaran la propiedad de sus viviendas o comercios linderos o cercanos $u$ otras situaciones similares),

\footnotetext{
8 "Una agrupación reúne a víctimas de la explosión de calle Salta", Diario El Ciudadano web, 9/05/14.

9 "Si gritamos en porque hace 9 meses que no nos dan una mano", por Santiago Baraldi, Diario La Capital, 10/05/14.
} 
pero además que los afectaban realmente de manera psíquica, física, económica, laboral.

Por otro lado, resulta llamativa la relevancia que adquirió en los testimonios y controversias públicas el lugar de la relación con los objetos. Sillones, departamentos o comercios fueron interpuestos como mediaciones que colaboraban en mermar la legitimación del dolor ante la pérdida. Los objetos fueron esgrimidos por algunos de los familiares de fallecidos como pruebas de la existencia de "escalas de dolor". Así, esas escalas fueron producidas con base en una contraposición entre dolor natural y esperable derivado del lazo de parentesco con los muertos y dolor circunstancial o artificio de una relación con lo sucedido que era necesario probar. La contraposición entre afectividad y racionalidad estuvo en el centro de las diferenciaciones entre las víctimas. Y esa contraposición, a su vez, estuvo mediada por el lugar de los objetos materiales en las vidas de los afectados por la explosión.

3) Un tercer eje se relaciona con la autenticidad del reclamo público de las víctimas. Los familiares de fallecidos sostenían la idea de que la asociación "6 de agosto" se había conformado a sus espaldas, "cuando ya tenían todo cocinado" y que "se colgaban" de las propuestas realizadas por los familiares de los fallecidos. Una de las familiares sostenía que el grupo de sobrevivientes y damnificados iba repitiendo las iniciativas que ellos lanzaban, una tras otra. Esta idea de duplicar las formas de reclamo (incluir el tema de la memoria cuando en un principio no lo habian contemplado, convocar "contramarchas" y atraer así a los medios de prensa, realizar las mismas peticiones que ellos ya habian hecho al poder político, etc.) sugiere la existencia de un original y una copia. Confrontados a la tarea de llevar adelante su reclamo de justicia en forma pública, los principales protagonistas pusieron de relieve las evaluaciones que realizaban al respecto. La idea de la duplicación de las acciones públicas sugiere cómo se van estableciendo fronteras que delimitan esos grupos en base a la legitimidad de la que se suponen portadores en función de distintos aspectos. Así, sostener que los otros "copiaban" cuestionaba la autenticidad o si se quiere, la "pureza" del reclamo de aquellos que no habían sufrido pérdidas fatales. Al mismo tiempo, contribuía al proceso inverso para aquellos que sí tenían familiares fallecidos, acrecentando su legitimidad para reclamar justicia. En este sentido, las controversias entre ambos grupos si bien no se prolongaron en el tiempo, dejaron entrever el tipo de actividad en la que 
se embarcan los actores que protagonizan una denuncia pública. En este caso un trabajo normativo (Barbot y Dodier, 2016) frente a determinados dispositivos, grupos e individuos que fueron dando forma a la idea de lo que significaba "ser un auténtico familiar de víctima".

Como se vio en todo el apartado, frente a distinto tipo de dispositivos se plantean posicionamientos que sirven para dar cuenta de la actividad que despliegan grupos e individuos en el sentido del trabajo de evaluación que realizan. Barbot y Dodier (2016) sugieren que este enfoque permite objetivar la base normativa que vuelve inteligibles y legítimos los posicionamientos de individuos y grupos frente a los dispositivos que se despliegan en forma posterior a una catástrofe.

\subsection{Intereses, dolor y legitimidad pública: la profundización de las tensiones en el grupo de familiares}

Dos aspectos del proceso recién descrito resultan claves para ayudar a comprender el devenir víctima. Por un lado, el que involucra un juicio moral acerca de los intereses con respecto a la reparación de daños materiales y por otro el que antepone el vínculo familiar y la muerte del ser querido como garantía de la autenticidad (y por ende la legitimidad) de "ser víctima". En las entrevistas, algunos familiares sugirieron de forma más o menos explícita que las distintas posturas frente a la reparación económica del daño era un tema que los dividía. En el caso de aquellos "que arreglaron", es decir, recibieron una compensación económica por parte de la empresa prestataria del gas y nunca participaron de las acciones públicas de demanda ni de los actos de homenaje o lo hicieron pocas veces, algunos entrevistados relativizaron las posiciones de quienes "no pudieron" hacer otra cosa. Más allá de estas actitudes, las posturas frente a los dispositivos de compensación o resarcimiento constituyeron un punto controvertido en la reflexión de algunos de ellos.

Lo que me parece que pasó es que 'pintó la plata', no todos los familiares creen que haya justicia, entonces dicen 'bueno, arreglemos' (...) porque este desgaste de los que seguimos la causa... porque seguir los plazos procesales es... viste, te consume. y entonces bueno, qué sé yo, hay familias que a lo mejor no tenían o no había nadie capacitado para salir y hacer y estar pendiente de todo esto o no querían o no creen en la justicia. (...) Pero eso, cada vez que hay una charla y hay un familiar enfrente y a lo mejor no puso abogado porque a lo mejor se quiere ahorrar la 'guita' y... eso sale. No es una 
cuestión tan liviana, viste, termina saltando (Entrevista de la autora a Laura, Rosario, 15/06/16)

En esta opinión de la entrevistada hay dos elementos importantes con relación al proceso de legitimación pública de las víctimas. Uno es el que conecta con la representación de voces ausentes como una labor que no todos son capaces de llevar adelante, dadas las dificultades y los costos personales que conlleva. Como indican Lefranc, Mathieu y Siméant (2008) la lógica de la delegación implica una serie de ambivalencias y límites derivados de la ausencia de aquellos que no están para denunciar lo sucedido. La selección de los portavoces dotados de facilidad para expresarse públicamente o para llevar a cabo tareas organizativas tiende a reproducir y consolidar desigualdades internas del grupo. Al mismo tiempo, colabora en dotarlos de un grado de especialización o profesionalización y favorecer distintos grados de autonomización de los mismos (2008).

El poder económico de la empresa, como ya se dijo, estuvo en el centro de las discusiones internas del grupo de familiares. Refiriéndose al "éxito" logrado por Litoral Gas en debilitar el reclamo, una familiar expresaba:

A diferencia de otros juicios, acá hay una empresa que sale a pagar, para mí esa fue la cuestión básica (...) Yo creo que lo han logrado, (...) salieron a pagar por ley del consumidor, ni siquiera salieron a pagar por una cuestión de que se atribuyen la responsabilidad (Entrevista de la autora a Laura, Rosario, 15/06/16).

La empresa colocó a los familiares en la categoría de consumidores afectados, es decir, intentó desplazarlos del marco de las responsabilidades, principal grilla de lectura del grupo que sigue el litigio en la justicia penal. Esto fue advertido por algunas de las principales portavoces del grupo de familiares, pero admitido como una estrategia que resultó efectiva gracias a las situaciones y posiciones singulares (en términos económicos, personales, emocionales) de cada familia. Así, las entrevistas y testimonios recogidos durante la investigación iban mostrando facetas a menudo contradictorias entre sí con relación al proceso de demarcación de los familiares de víctimas. Esto no es algo novedoso en las movilizaciones de víctimas sino una dimensión que ha 
sido extensamente trabajada en la Argentina y en otras partes del mundo ${ }^{10}$.

Un aspecto adicional que tiene un lugar relevante en la profundización de las diferenciaciones y tensiones internas al grupo de familiares, se relaciona con las posiciones y evaluaciones frente a los dispositivos desplegados en el ámbito judicial.

Creer en "la justicia" como algo a ser alcanzado a través de las acciones públicas y mediante el proceso judicial, contrastaba entre los familiares con una crítica hacia la forma de funcionamiento del sistema de justicia. Este contraste es usual entre los grupos que expresan reclamos en el espacio público y es posible acceder a él a través de las declaraciones en la prensa o de la observación de sus propias acciones directas (en este caso, acampes frente a los tribunales, pintadas, ingreso al edificio para golpear puertas de las oficinas, etc.). Así, en una reunión de un grupo de familiares con la fiscal y co-fiscal de la causa, se pudo observar dicho contraste. Según se expresó se los convocaba un día antes del tercer aniversario de la explosión dada la significación de la fecha y debido a que serían requeridos por la prensa para efectuar declaraciones. Por estos motivos, se consideraba necesario que se mostraran unidos. Con esto se pedía no hacer públicas las diferencias internas entre familiares y evitar criticar el accionar de la fiscalía para que no hubiera fisuras en la estrategia judicial. Las fiscales creían que ello podía contribuir a generar una desventaja en el juicio oral y público que se avecinaba.

Los familiares mantuvieron intercambios tensos, en algunos momentos ásperos con ambas funcionarias. Acordaban que debían mostrar unidad hacia afuera y en críticas hacia las estrategias de los abogados de la empresa privada, que calificaban como espurias. Pero las críticas hacia el accionar de la justicia fueron desplegadas en forma abierta e indignada frente a las fiscales de la causa. El profundo descontento con

\footnotetext{
${ }^{10}$ Tanto los trabajos de Jelin (2007), como los de Pita (2010) y Pereyra (2005) constituyen referencias con relación al papel de los familiares en las movilizaciones de víctimas de distintos tipos de acontecimientos y procesos. También he trabajado estos procesos en Schillagi (2009). Por otra parte, tal como indica Hoffman (2008) para el caso de los desastres, existe siempre una fase de agrupamiento entre las víctimas, pero eso no equivale a dejar de lado determinadas diferenciaciones, grados, escalas, que son establecidas en base a distintos criterios (por ejemplo, en el incendio en Oakland era diferente si se había perdido toda la casa o sólo una parte y en el caso de Yungay estudiado por Oliver-Smith (citado en Hoffman, 2008) las víctimas de la avalancha adquirieron un estatus diferente del de los sobrevivientes del terremoto).
} 
la imposibilidad de "Ilegar más arriba" con las imputaciones alcanzado al personal jerárquico de la empresa, las dilaciones, la falta de investigación más profunda que incluyera aspectos que no habían sido tomados por la fiscalía fueron los pilares de las críticas.

Los presentes en la reunión con las fiscales maniobraron entre la actitud de ponerse a disposición del trabajo de la dependencia judicial y el desacuerdo con las formas de lo actuado hasta el momento; entre el dolor por la pérdida de un ser querido y la impotencia que les provocaba su "nueva familiaridad" con el funcionamiento del sistema judicial. Varias veces alzaron la voz para decir "acá la justicia no existe". Una madre le recordó a la fiscal que ella a su hijo no lo iba a recuperar jamás y agregó: "¡vos sos madre!" interpelando una identidad diferente de la funcionaria judicial.

Los diálogos mantenidos en la reunión mostraban que funcionarios judiciales y familiares de víctimas pueden, en algunos momentos, mantener acuerdos o sostener desacuerdos apelando a intereses y sensibilidades variables. El modo de vinculación y las evaluaciones realizadas por ambos tipos de actores son heterogéneas y ambivalentes, siendo unas veces las bases para acciones o posiciones públicas conjuntas y otras, obstáculos o límites para las mismas. Identidades como las de familiares de víctimas y funcionarios judiciales pueden ser cuestionadas a través de interpelaciones a la calidad de madres de las funcionarias o también, realizando críticas sobre el lugar asignado a las víctimas en el proceso judicial, acusándolas de no cumplir con sus expectativas de justicia.

Este análisis en el seno del dispositivo judicial nos permite analizar el modo en que se presenta a los individuos en tanto sistema burocrático o aparato estatal. Pero también es posible analizar el modo en que el dispositivo se presenta materializado en espacios físicos que adquieren significaciones particulares para cada uno de los involucrados y para el grupo en general. Así, una familiar realizaba la siguiente comparación:

Y... entrar al tribunal es peor que entrar a... no sé... al mismo cementerio... un desastre. La verdad que es un lugar muy feo, donde hay gente muy fea y la verdad que reina la injusticia (Entrevista de la autora a Laura, Rosario, 15/06/16)

En esta apreciación emerge una idea que en cierta medida contribuye a reforzar la cuestión sobre la ambivalencia en los posicionamientos y 
evaluaciones de los familiares al interior de determinados dispositivos. EI proceso social que subyace a la conformación de un familiar de víctima como tal, en tanto actor público, está relacionado con el trajinar por diferentes ámbitos privados y públicos y con sensibilidades personales contradictorias frente a la búsqueda de justicia y la vinculación con el ámbito judicial. Este itinerario muestra, a mi entender, cómo la relación con los dispositivos que emergen en el marco de catástrofes o hechos similares no es de carácter general o universal sino que debe ser analizada en cada caso particular y en cada escenario histórico específico.

\section{LAS VÍCTIMAS Y LA POLÍTICA}

\subsection{El Estado en la catástrofe}

Las críticas al mundo de la política sugieren una pista para pensar cómo se fue configurando socialmente el carácter de víctimas en el presente caso. La apelación a las autoridades para que resolvieran distintas situaciones que afectaban a los familiares, convivía con una crítica al poder político.

"Si bien tenía de la justicia y de la política cierto imaginario de lo que era y de cómo funcionaba, la verdad, que vivir hoy de adentro la política y vivir de adentro, ehh, el poder judicial, nos quedamos cortos con lo que pudimos imaginar, de lo que es la... ehh, de lo que eran los negocios, de lo que es la corrupción, de lo que es la ineficacia. Por eso es que nosotros decimos que en calle Salta lo que explotó no es un edificio, sino lo que explotó fue la corrupción"11.

En varias oportunidades, los familiares recurrieron a relatos en los que el hecho catastrófico operaba como impulsor de un cambio de perspectiva respecto de las instituciones públicas. No sólo en el sentido de una crítica retórica general hacia la política, la justicia o las distintas instancias estatales de atención a la víctima; también como modificación del tipo de interacción o de vinculación con dichas esferas (enfrentamiento, distanciamiento, colaboración, participación) que se iban verificando sin que los familiares se lo plantearan necesariamente como un objetivo de sus propias acciones, es decir, como una estrategia.

\footnotetext{
${ }^{11}$ Intervención de una familiar de calle Salta en un panel realizado en el marco de las Jornadas "Derechos Humanos y Psicología". Organizadas por la Facultad de Psicología de la Universidad Nacional de Rosario, setiembre de 2015.
} 
En la intervención arriba citada, una de las familiares hacía referencia a un "antes" en el que tenía un "imaginario" sobre la política o la justicia (en el sentido de una exterioridad respecto de esos ámbitos). Pero había una alusión al "después" que marcaba el inicio de un cambio de posición, un "vivir desde adentro" los mundos de la política y la justicia. Este proceso marcó una modificación de papeles y de lugares de los familiares a través del tiempo, que colaboró en la producción de una figura particular de las víctimas indirectas ${ }^{12}$.

Se trata de una figura ambivalente con relación a su posición social y a la construcción de su legitimidad. Por un lado, debe mostrar su inocencia al resto de la sociedad, en el sentido de una pasividad y una exterioridad respecto del daño sufrido y como tal debe seguir hablando como ciudadano o ciudadana común y dirigiéndose a los demás desde esa posición. Pero por otro lado, al marcar a la catástrofe como punto de quiebre y mostrar que sus conocimientos acerca de las instancias públicas se han acrecentado y que su reclamo es extensivo al resto de la sociedad porque "todos" pueden correr el mismo riesgo, se inicia un proceso por el cual la figura de la víctima va perdiendo su ingenuidad política o en todo caso, una supuesta distancia previa con la política.

En el marco de lo que Boltanski (2007) llama el "régimen de la justicia", la violencia de la acusación hacia los otros (que es siempre retrospectiva pues supone una reconstitución del pasado) sólo puede sostenerse si (en este caso, la víctima) se somete a un proceso de des-singularización y de generalización, que marque una distancia respecto de los intereses de una persona singular para ponerla al servicio del interés común. En otras palabras, el precio de ejercer la violencia que conlleva la acusación pública es reducir las pasiones personales y la exhibición de los intereses singulares poniéndolos al servicio de la demostración de que son los intereses generales los que se han visto afectados.

Si se traslada el foco de atención desde las posiciones y evaluaciones de las víctimas con relación a la política (y los intereses generales) a la

\footnotetext{
${ }^{12}$ Quizás se pueda pensar en las diferenciaciones de las víctimas en el sentido en que es presentado por Camargo da Silva (2003) al analizar el desastre radioactivo de Goiânia: un sufrimiento que el estado y los expertos tienden a limitar inscribiéndolo en una versión oficial y otro más soterrado, encarnado en el cuerpo y los recuerdos de los sobrevivientes. Aunque aquí no tomo esa dimensión de análisis, es interesante pensarla como parte de las ambigüedades y contradicciones que encierra el proceso de producción social de las víctimas.
} 
descripción de las acciones y medidas que implementaron las autoridades, aparecen otras cuestiones. En efecto, en la arena política la reacción no se hizo esperar. Los partidos acordaron suspender los actos de campaña y cierre de las elecciones primarias abiertas, simultáneas y obligatorias previstas para el 11 de agosto de $2013^{13}$. Se decretaron dos días de duelo nacional y tres a nivel provincial.

Una de las primeras medidas tomadas por el exgobernador Antonio Bonfatti fue declarar en estado de emergencia a la cuadra donde ocurrió el siniestro, delimitando una zona de desastre donde no se podía residir. Tanto la intendenta de la ciudad, Mónica Fein, como el gobernador declararon como prioridad "encontrar a los ausentes", refiriéndose a las personas que podían estar atrapadas bajo los escombros. El viaje de la entonces presidenta Cristina Fernández a Rosario y su posterior reunión con las autoridades locales y provinciales, marcó la magnitud de lo sucedido. Luego de esa reunión, se dieron a conocer algunas de las primeras medidas coordinadas por los tres niveles de gobierno. Las autoridades anunciaron créditos y ayudas relativas a la reparación de daños materiales y económicos apuntando a la figura de los "damnificados".

El Estado nacional tomó la iniciativa habilitando una línea de crédito específica llamada "línea damnificados Rosario" en el marco del PRO.CRE.AR, un plan nacional de créditos para la vivienda, e implementándola a través de una entidad oficial como el Banco Hipotecario Nacional. A ella podían acceder aquellos que lo solicitaran pero con la posterior verificación "a través de un formulario" de que se trataba de damnificados por los hechos ocurridos. En dicho procedimiento de verificación intervenía no sólo personal del Banco sino también "equipos de la Administración Nacional de la Seguridad Social (ANSES)" ${ }^{\prime 14}$. Se trataba de créditos hipotecarios para la adquisición, construcción o refacción de viviendas o comercios.

Por otra parte, las autoridades municipales y provinciales anunciaron que los residentes de calle Salta entre Oroño y Balcarce, excluyendo el edificio siniestrado, iban a recibir 20 mil pesos para alquilar una vivienda, así como subsidios y créditos por 50 mil pesos para compra de enseres y

13 "El arco político nacional también decidió suspender las campañas", Diario La Capital, 08/08/13.

14 "El gobierno provincial anunció nuevos subsidios y créditos para afectados", Diario La Capital, 09/08/13. 
muebles. En cuanto a los comercios de la zona, se anunció que se iban a ir habilitando de forma progresiva y que el estado provincial se haría cargo de la limpieza y reparación de los lugares ${ }^{15}$.

En setiembre de 2013 se aprobó por unanimidad un proyecto de ley para crear un "Fondo Especial para la Asistencia y Reparación a los damnificados de la Tragedia de calle Salta 2141 de Rosario" ${ }^{16}$. Este fondo tenía como propósito principal financiar un régimen de reparación excepcional destinado a atender los deterioros o pérdidas ocasionadas por el hecho. Distinguía entre "afectación de la vida" (se otorgaba un beneficio único por muerte que tuviera "causalidad inmediata con la explosión"), deterioros o pérdidas causadas en inmuebles de residencia y muebles accesorios y deterioros o pérdidas causadas en otros bienes muebles. Por otra parte, en el ámbito parlamentario provincial, se impulsó una ley (oficializada en diciembre de 2013) para eximir del pago de impuestos inmobiliarios y de los servicios de electricidad y agua corriente a los inmuebles afectados por el siniestro y del pago de patente única a los vehículos afectados. En el texto de la ley se indicaba que a los efectos de la acreditación sería "válida toda documentación que informe la Municipalidad de Rosario y/o la oficina del ámbito Provincial que haya intervenido en las operaciones de relevamiento de los damnificados" (Ley provincial 13381, 2013).

Además de estas iniciativas, comenzaron a desplegarse operativos orientados a la cuantificación de los daños económicos sufridos. Las agencias estatales encargadas de llevar adelante estas acciones, que atravesaban distintas áreas de gobierno, se agruparon en 25 equipos coordinados por la Secretaría de Planeamiento del municipio con el objetivo de dar cobertura a aquellos que no poseían seguro de hogar y como complemento para los que sí tenían una póliza.

La atención psíquica de las personas involucradas también fue objeto de acciones estatales. Los equipos de salud mental dependientes del Ministerio de Salud de la provincia y también de la Secretaría de Salud de la municipalidad tuvieron un papel clave en la asistencia y contención de familiares, sobrevivientes y afectados por la catástrofe. A través de

\footnotetext{
15 "El Estado cuantifica el destrozo", Diario La Capital, 09/08/13.

${ }^{16}$ Informe de gestión del Senador Nacional del Partido Socialista Rubén Giustiniani, diciembre 2015. En el pedido se solicitaba una partida especial de $\$ 70$ millones del Presupuesto Nacional que serían transferidos del Ministerio del Interior y Transporte a la Municipalidad de Rosario.
} 
un despliegue de operativos en distintos puntos de la ciudad (la zona del siniestro, el Centro de Especialidades Médicas Ambulatorias de Rosario y el Instituto Médico Legal) los profesionales integrantes de los equipos fueron recibiendo demandas y ofreciendo su intervención desde el momento inicial hasta varios meses después ${ }^{17}$.

Como puede verse, acciones políticas de distinta índole fueron dando un sentido particular a lo ocurrido y al mismo tiempo fueron delimitando las condiciones de acceso o exclusión con respecto a determinados dispositivos. Así, las víctimas se configuran como tales en entramados complejos de actores que dan sentido a su condición de tales y no a partir de un acontecimiento que las pone en relación entre sí, lanzándolas a la acción colectiva o judicial de manera automática. Las autoridades, a través de las voces de funcionarios y de acciones y procedimientos específicos, tomaron parte en una forma de producir el acontecimiento y sus protagonistas.

\subsection{Los familiares y los distintos tipos de relación con los niveles estatales}

Los familiares adoptaron posturas y realizaron evaluaciones frente a cada dispositivo y construyeron diferentes relaciones con las instancias políticas. Para entender este punto es preciso reconstruir brevemente el marco general del reclamo.

Las marchas en demanda de justicia y en conmemoración de las víctimas se iniciaron a dos semanas de la explosión y se fueron repitiendo mes a mes durante todo el primer año ${ }^{18}$. Se realizaron bajo la consigna del silencio y portando velas y pancartas con fotos de los fallecidos. A un mes de ocurrido el hecho hubo marchas en otras plazas del país y a través de las redes sociales y de los medios de comunicación, se invocaron otros casos como el accidente ferroviario de Once, el

\footnotetext{
${ }^{17}$ Para profundizar en el tema se puede consultar: "Es importante estar allí", Diario Rosario 12, 08/08/13; "Cómo funciona la asistencia emocional en los días del espanto después del desastre", Diario La Capital, 18/08/13; "Una confianza que fue fundamental", Diario La Capital, 18/08/13.

${ }^{18} \mathrm{~A}$ fin de tener un panorama general de las acciones colectivas realizadas por los familiares, pueden consultarse, entre otros: "En la emotiva marcha a Litoral Gas, ya se llamó a una próxima el 6 de setiembre", Diario La Capital, 23/08/13.; "Hoy habrá una marcha e inaugurarán un paseo", Diario La Capital, 06/10/13; "Nueva marcha a cuatro meses de la tragedia", Diario La Capital, 06/12/13; "Salta 2141: nueva marcha para exigir justicia", Diario La Capital, 06/02/14; "Rosario conmemora hoy la peor tragedia de su historia", Diario La Capital, 06/08/14.
} 
incendio de Cromañón o las inundaciones de La Plata ${ }^{19}$. A estas marchas se sumaron luego los actos de homenaje y conmemoración organizados por los familiares en ocasión de cada aniversario.

Las acciones directas (concentraciones, acampes, pintadas, vigilias) se concentraron principalmente en torno a tres ámbitos: la empresa Litoral Gas, los tribunales provinciales de justicia y el ENARGAS ${ }^{20}$. Los familiares dirigieron sus demostraciones de protesta sobre la base de un trabajo de evaluación de las responsabilidades específicas que atribuían a cada actor. En ese sentido, el caso estudiado tiene una particularidad con relación a otras movilizaciones de víctimas en la Argentina. Mientras que en otras experiencias de movilización de víctimas la responsabilidad causal coincide con la responsabilidad política ${ }^{21}$, en casos como el de la explosión en Rosario las instituciones privadas son consideradas como causantes directas del problema. Las instancias estatales se ubican en el plano de la responsabilidad ligada a su obligación de actuar en pos del interés común, dando respuestas o tomando medidas respecto del problema (Gusfield, 2014) 22 .

Las autoridades políticas fueron y siguen siendo interpeladas con relación a su papel en los controles, la prevención y las acciones posteriores al suceso. El reclamo a los políticos fue canalizado a través de discursos en ocasión de aniversarios, declaraciones a los medios, petitorios o cartas presentadas en ámbitos ejecutivos o legislativos o en reuniones que mantuvieron con el entonces gobernador, con la intendenta y con legisladores provinciales y concejales de la ciudad.

\footnotetext{
${ }^{19} \mathrm{Ver}$ "A un mes de la explosión la marcha por la explosión se multiplica en el país", La Capital, 06/09/13.

${ }^{20}$ Las controversias públicas, las formas de relacionamiento y el litigio judicial entre los familiares y la empresa Litoral Gas por un lado y el ENARGAS por otro, constituyen dimensiones muy relevantes del caso estudiado, que desarrollo en el marco de una investigación que excede los objetivos de este artículo.

${ }^{21}$ Como es el caso de las movilizaciones de víctimas de violencia institucional o las más paradigmáticas, de los organismos de derechos humanos que denuncian los crímenes de lesa humanidad cometidos por el Estado argentino durante la dictadura cívico-militar de 1976 a 1983.

${ }^{22}$ La responsabilidad causal es objeto de creencia o cognición, expresa la secuencia de hechos relevantes o explicativos para la existencia de un problema. La responsabilidad política es materia de medidas políticas, alude a los actores individuales o institucionales que están obligados a hacer algo al respecto, a fin de erradicar o aliviar la situación problemática (Gusfield, 2014).
} 
Este conjunto de posiciones y de acciones frente al Estado no se puede analizar de manera general, considerándolo como una unidad indivisible y monolítica. El tipo de relación establecida por el grupo de familiares de calle Salta fue variando en el tiempo y se desarrolló en planos superpuestos de distanciamiento, acercamiento o colaboración. Las vinculaciones que se establecieron sufrieron variaciones de acuerdo a los niveles de gobierno y a las expectativas que los movilizaban en distintas fases de la denuncia pública y judicial que llevaban adelante. Además, los familiares no se relacionaron con las instancias estatales como un grupo homogéneo. Las particularidades comenzaron a surgir con el correr del tiempo y las posturas divergentes con respecto al papel del Estado o de algunos ámbitos institucionales.

Tal fue el ejemplo de una de las familiares, Laura, que fue convocada para integrar los equipos de una oficina municipal de atención a las víctimas, luego convertida en una dirección provincial que abordaba la misma temática: el tipo de relación sufrió una modificación sustancial entre los familiares; mientras algunos se mantuvieron por fuera de las estructuras estatales, otros fueron convocados a participar en equipos relacionados con la temática de la atención y contención a víctimas de diferentes tipos de hechos. El Centro de Atención a Víctimas de la violencia, en donde comenzó trabajando Laura, fue creado en junio de 2015 a través de un decreto municipal. En sus primeras declaraciones como parte de ese equipo, ella expresaba:

"El familiar que viene no va a tener que decirme qué está pasando ya que transité por estos caminos, voy a poder ayudarlo para que no tenga que recorrer caminos que a veces son tan tortuosos"

En consonancia con esta idea, la funcionaria a cargo de la Dirección Provincial de Atención a Víctimas del gobierno de Santa Fe, opinaba así sobre la integración de los equipos estatales:

Nosotros hoy contamos con 3 familiares de víctimas que trabajan actualmente en la Dirección y están

\footnotetext{
23 "Fein redobló apuesta en políticas de prevención y asistencia a víctimas de la violencia". Disponible en: http://www.rosarionoticias.gob.ar, 02/06/15. Consultable en: http://www.rosarionoticias.gob.ar/page/noticias/id/30714/title/Fein-redobl\%C3\%B3-apuesta-enpol\%C3\%ADticas-de-prevenci\%C3\%B3n-y-asistencia-a-v\%C3\%ADctimas-de-la-violencia. última consulta: 11/02/17.
} 
profesionalizados en eso, en lo que es la atención a familiares de víctimas por el proceso particular que han tenido ellos. Entonces esa capacidad profesional y de una alta sensibilidad (...), no porque tengas que acompañar desde el dolor, sino porque esa sensibilidad te va a permitir acercarte hasta el lugar donde esa persona te demuestre qué es lo que realmente está necesitando (Entrevista de la autora a una funcionaria provincial del área de atención a víctimas, Rosario, 26/07/16).

Al describir el proceso de profesionalización de los familiares integrantes del equipo, la funcionaria coloca en el centro del interés estatal la experiencia personal de los mismos, como un modo de acceder mejor a la comprensión de las necesidades de otras víctimas. Este aspecto que aquí sólo será señalado pero que constituye una línea de indagación a seguir, es interesante en la medida en que se relaciona con los modos en que va configurándose la legitimidad de la figura de las víctimas. Legitimidad que no sólo emana del dolor sufrido por la pérdida de un ser querido, sino que también es configurada por los dispositivos estatales (o de otra indole) con los que cada familiar o grupo entra en contacto. Como sostienen Lefranc, Mathieu y Siméant (2008) los relatos de los que son considerados víctimas conforman a través del testimonio un modo de conocimiento de la realidad cuya legitimidad se ha ido acrecentando a través del tiempo. La idea subyacente sería ¿quién mejor que el que lo ha vivido para poder explicar o entender?: el conocimiento del testigo podría considerarse un "conocimiento a través del cuerpo o por el cuerpo" (2008: 16). Así, en algunos casos, el sufrimiento incorporado por los familiares de las víctimas puede ser trastocado en un saber que el Estado considera valioso para ejercer funciones públicas o para desplegar determinados dispositivos.

\section{GobieRno POR DISPOSITIVOS. ¿CUÁL ES EL PAPEL DE LAS VÍCTIMAS?}

A través del análisis desarrollado intentamos mostrar algunas de las dimensiones mediante las cuales los familiares de víctimas de una catástrofe iniciaron un proceso de representación de los ausentes que los fue configurando como víctimas. Las controversias y diferencias dentro de los grupos de familiares resultaron claves para desnaturalizar la idea de un pasaje automático del sufrimiento a la acción pública o a la 
formación de grupos de víctimas homogéneo, organizado y movilizado en torno a objetivos comunes que tendrian sustento en el dolor compartido. A la vez, el análisis pretendió indicar algunas pistas que deben ser profundizadas pero que parecen importantes para comprender a través de qué tipo de procesos un grupo conformado en torno al reclamo de justicia por la muerte de sus familiares es considerado un "grupo de víctimas". En dicho proceso intervinieron múltiples actores aunque aquí sólo se ha profundizado en la relación con las autoridades públicas.

Como vimos a lo largo del texto, los dispositivos gubernamentales hicieron las veces de mediaciones, erigiéndose en canales que facilitaron o hicieron posible la acreditación de condiciones o de procesos previos al hecho catastrófico, conteniendo las situaciones de dolor subjetivo a través de protocolos de atención psíquica u otorgando facilidades materiales que permitieran retomar la vida ordinaria. Clasificando lo sucedido como catástrofe y gobernando por dispositivos, el Estado participaba de manera simultánea en la restauración de un orden previo y en el proceso de producción social de las víctimas. Es a partir de una idea de catástrofe que es posible intervenir de determinada forma y es a partir de ese sentido de disrupción radical de la vida cotidiana en la que el dolor, el sufrimiento y la pérdida cobran total centralidad que puede ubicarse parte del proceso de constitución de las víctimas como tales.

Así, los dispositivos de distinto tipo con los que entraron en contacto los familiares a partir de la catástrofe jugaron un papel clave en el proceso de producción social de las víctimas. Pero entrar en contacto no significó en este caso una aceptación pasiva de secuencias preconcebidas para enfrentar el desastre ocurrido, sino una amplia variedad de modos de evaluar, sopesar y adoptar posiciones frente a ellos. El análisis de los dispositivos requiere no sólo una descripción externa del modo de funcionamiento o las características de estas entidades sino una indagación de los distintos modos en que los familiares se mueven en el interior del dispositivo, esto es, forjan opiniones, se organizan, se oponen o expresan sensibilidades ambivalentes frente a los mismos.

Esto permite captar las posibilidades de actuar que pueden tener los individuos y grupos frente a estas secuencias temporales que son desplegadas tanto por las autoridades como por entidades privadas. En 
tal sentido, en el texto se han expuesto los cuestionamientos y las interpelaciones al interior de determinados dispositivos (por ejemplo, el judicial) que no se hicieron públicos sino que permanecieron dentro del grupo de familiares. Este es un elemento importante para reflexionar acerca de los límites y constreñimientos que pueden desprenderse de un mismo dispositivo y que no siempre son aceptados pasivamente por las víctimas. También es un punto importante para no perder de vista que las finalidades de los dispositivos no deben ser consideradas como esenciales sino que en cada caso es preciso indagar el proceso por el que esa finalidad se constituye o cambia en el tiempo y el papel que pueden jugar las víctimas, así como otros actores sociales, en él.

\section{BIBLIOGRAFÍA}

Barbot, J., \& Dodier, N. (2016). La force des dispositifs. Annales. Histoire, Science Sociales, 2(71), 421-450.

Boltanski, L. (2007). La souffrance à distance. Paris: Gallimard.

Camargo da Silva, T. (2003). Memória corporificada, marcas urbanas e esquecimento: a descontaminação simbólica no caso do desastre de Goiânia, VIII Reunião de Antropólogos do Norte e Nordeste (ABANNE). São Luís (MA), Brasil, 1 a 4 de julho.

Clavandier, G. (2010). Un rétour sur la catastrophe. Nouveau regard, nouvel objet pour l'anthropologie. Le Portique, 22, https://leportique.revues.org/2073.

Dodier, N. (2007). Postscript. Thinking (by way of) Disaster. In J. Langumier \& S. Revet (Eds.), Governing Disasters. Beyond Risk Culture (pp. 221-244). New York: Palgrave Macmillan.

Fassin, D., \& Rechtman, R. (2007). L'Empire du traumatisme. Enquête sur la condition de victime. Paris: Flammarion.

Gusfield, J. (2014). La cultura de los problemas públicos. El mito del conductor alcoholizado versus la sociedad inocente. Buenos Aires: Siglo XXI.

Hoffman, S. (2008). The Worst of Times, the Best of Times: Toward a Model of Cultural Response to Disaster. In A. Oliver-Smith \& S. Hoffman (Eds.), The Angry Earth: Disaster in Anthropological Perspective (pp. 134-155). New York: Routledge.

Informe de gestión del Senador Nacional del Partido Socialista Rubén Giustiniani, diciembre 2015, s/d. 
Jelin, E. (2007). Víctimas, familiares y ciudadano/as: las luchas por la legitimidad de la palabra. Cadernos Pagu, 29, 37-60.

Langumier, J., \& Revet, S. (Eds.). (2015). Governing Disasters. Beyond Risk Culture. New York: Palgrave Macmillan.

Lefranc, S., Mathieu, L., \& Siméant J. (2008). Les victimes écrivent leur Histoire. Introduction. Raisons Politiques, 2(30), 5-19.

Oliver-Smith, A., \& Hoffman S. (2008). The Angry Earth: Disaster in Anthropological Perspective. New York: Routledge.

Oliver-Smith, A., et al. (2016). The social construction of disaster risk: Seeking root causes. International Journal of Disaster Risk Reduction, http://dx.doi.org/10.1016/j.ijdrr.2016.10.006.

Pita, M.V. (2010). Formas de morir y formas de vivir. El activismo contra la violencia policial. Buenos Aires: Ediciones del Puerto.

Pereyra, S. (2005). ¿Cuál es el legado del movimiento de derechos humanos? El problema de la impunidad y los reclamos de justicia en los noventa. In F. Schuster et al. (Eds.), Tomar la palabra. Estudios sobre protesta social y acción colectiva en la Argentina contemporánea (pp. 151-191). Buenos Aires: Prometeo.

Schillagi, C. (2009). 'Inseguridad', reclamos al Estado y actuación pública de organizaciones y familiares de víctimas de delitos en la Argentina (2004-2006). In G. Delamata (Coord.), Movilizaciones sociales ¿nuevas ciudadanias? Reclamos, derechos, Estado en Argentina, Bolivia, Brasil (pp. 109-159). Buenos Aires: Biblos.

Zenobi, D. (2014). Familia, política y emociones. Las víctimas de Cromañón entre el movimiento y el Estado. Buenos Aires: Antropofagia. 